\title{
An exploration of the views of paramedics regarding airway and resuscitation research
}

\author{
Matt Thomas \\ From London Trauma Conference 2014 \\ London, UK. 9-12 December 2014
}

\section{Introduction and aims}

Paramedics are a skilled group of clinicians with expertise in cardiac arrest. Our research group has complete a trial to comparing two supraglottic airway devices with current practice during cardiac arrest (REVIVEAirways). This is a highly contentious topic amongst UK paramedics, The study aimed to explore the existing customs and beliefs surrounding intubation and resuscitation by UK paramedics.

\section{Method}

We used a two level qualitative approach, conducting interviews and focus groups with paramedics. Focus groups discussed the themes arising from the interview data, developing a deeper understanding and providing insight and recommendations for future research and policy development.

\section{Setting}

The study took place within Great Western Ambulance Service NHS Trust (GWAS). The University of the West of England, Bristol, provided sponsorship and governance. As the trial was on NHS staff ethical committee approval was not required.

\section{Selection \& data collection}

Paramedics were sampled purposefully to account for differing training and subsequently customs and beliefs and participation or not in the large trial. Supplementary

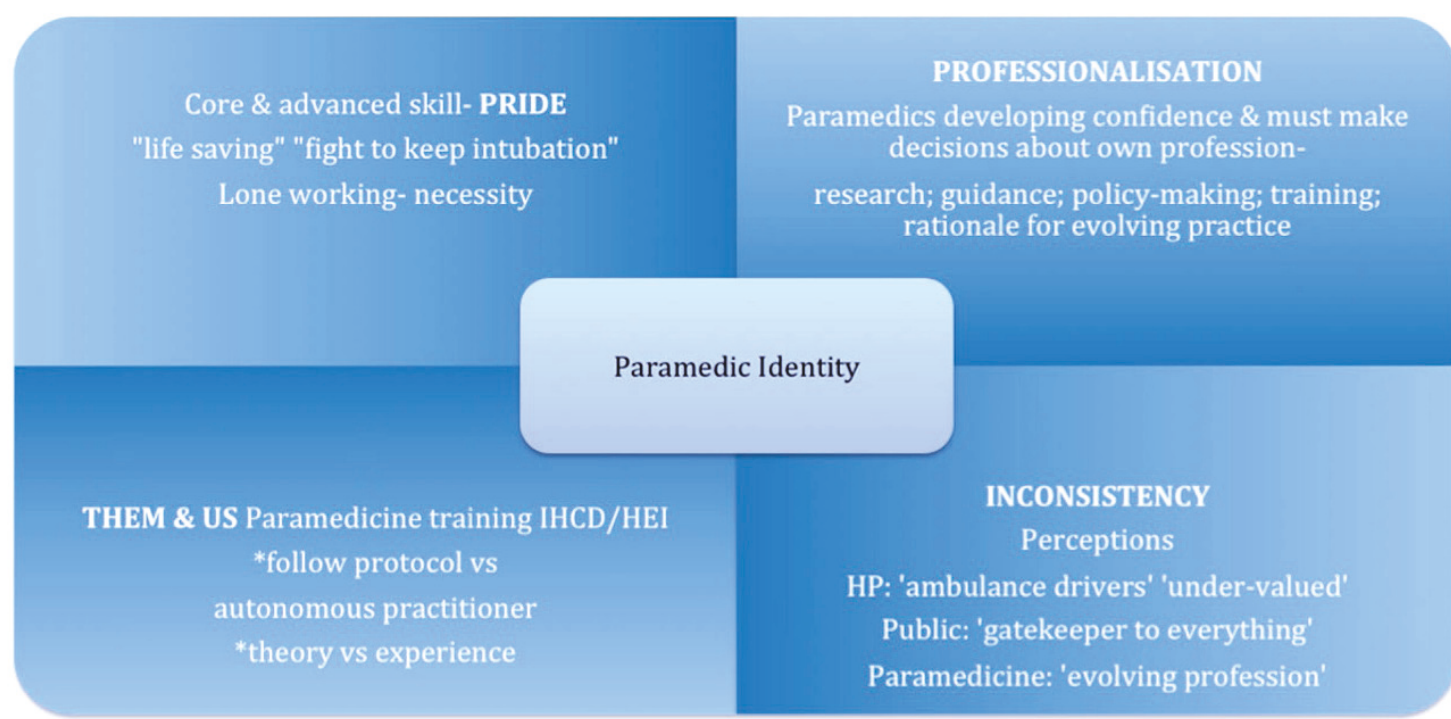

Figure 1 Paramedic identity

Correspondence: mjcthomas@gmail.com Great Western Air Ambulance, Bristol, UK 
snowballing was used to further identify interested/ eligible paramedics. There were 34 study participants, with 17 paramedic interviews; followed by 5 focus groups with a further 17 participants. Data saturation was reached.

\section{Results}

Thematic analysis was conducted. This was done in 2 stages: after interviews as a guide for focus groups, and after the focus groups. Early analysis suggests that this group of paramedics were pro-research even though some had not taken part in the earlier trial. They described four aspects of paramedic identity (figure 1).

Specific discussion regarding intubation was focussed upon patient safety, with debate regarding the necessity of intubation in comparison to the use and success of other techniques. This stimulated concern regarding lack of training and subsequent skill fade through lack of rehearsal and competency testing. This invigorated debate about whether all paramedics should perform this task. Views differed with some vehemently protective of this skill, while others were more sanguine about this in relation to other recent skills. Frequent reference was made to the difficult situations paramedics find them selves in, specific injuries or illnesses and co-morbidities and the difficulty in retrieval of patients as a rationale for retaining the skill.

\section{Conclusion}

Future trials in prehospital care must involve paramedics and ensure their professionalism is understood and respected.

Published: 11 September 2015
doi:10.1186/1757-7241-23-S2-O6

Cite this article as: Thomas: An exploration of the views of paramedics regarding airway and resuscitation research. Scandinavian Journal of

Trauma, Resuscitation and Emergency Medicine 2015 23(Suppl 2):06.
Submit your next manuscript to BioMed Central and take full advantage of:

- Convenient online submission

- Thorough peer review

- No space constraints or color figure charges

- Immediate publication on acceptance

- Inclusion in PubMed, CAS, Scopus and Google Scholar

- Research which is freely available for redistribution

Submit your manuscript at www.biomedcentral.com/submit 